\title{
Biological changes in auditory function following training in children with autism spectrum disorders
}

Nicole M Russo ${ }^{1,2,3+}$, Jane Hornickel ${ }^{1 *+}$, Trent Nicol' ${ }^{1}$, Steven Zecker ${ }^{1}$, Nina Kraus ${ }^{1,4,5}$

\begin{abstract}
Background: Children with pervasive developmental disorders (PDD), such as children with autism spectrum disorders (ASD), often show auditory processing deficits related to their overarching language impairment. Auditory training programs such as Fast ForWord Language may potentially alleviate these deficits through training-induced improvements in auditory processing.
\end{abstract}

Methods: To assess the impact of auditory training on auditory function in children with ASD, brainstem and cortical responses to speech sounds presented in quiet and noise were collected from five children with ASD who completed Fast ForWord training.

Results: Relative to six control children with ASD who did not complete Fast ForWord, training-related changes were found in brainstem response timing (three children) and pitch-tracking (one child), and cortical response timing (all five children) after Fast ForWord use.

Conclusions: These results provide an objective indication of the benefit of training on auditory function for some children with ASD.

\section{Background}

Children with Pervasive Developmental Disorders (PDD), such as children with autism spectrum disorders (ASD), autism, Asperger's syndrome, or Pervasive Developmental Disorder - Not Otherwise Specified, demonstrate some level of impairment in the social and communicative use of language, social interactions, and imaginative and symbolic play, with an onset prior to the age of 3 years [1-3]. Some children with ASD have difficulties processing speech in background noise $[4,5]$. To this effect, emerging evidence suggests that the neural encoding of speech sounds may be impaired in these children [6-11]. Some children with ASD exhibit auditory brainstem processing deficits specific to speech stimuli $[9,10]$, such as deficits in neural synchrony (timing) and phase locking (periodicity encoding; transcription of pitch contour), as well as degradation of the morphology of the

\footnotetext{
* Correspondence: j-hornickel@northwestern.edu

† Contributed equally

'Auditory Neuroscience Lab, Department of Communication Sciences,

Northwestern University, Evanston, IL, USA www.brainvolts.northwestern.edu

Full list of author information is available at the end of the article
}

responses in quiet and background noise, despite normal click-evoked brainstem responses. Reduced amplitude, delayed timing, and overall degraded morphology of cortical responses to speech syllables have also been reported in children with ASD relative to typically-developing (TD) children [6-8,11,12].

Several interventions targeting language, social skills, and auditory processing have been implemented for children with ASD (e.g., [13-18], see also the National Autism Center's National Standards Project report [19]). Given the variable nature of ASD, it is not surprising that treatment options and success vary across individuals. Thus, although studies show promise of success, further research is still needed to distinguish appropriate interventions for a specific child.

Fast ForWord Language (FFW; Scientific Learning Corp.; composed of Fast ForWord Language and Language to Reading) is a commercially available language training program consisting of seven games focusing on perceptual discrimination and language comprehension. The program provides auditory-focused training, including lessons in listening and sound sequencing, auditory 
attention, auditory discrimination, phoneme discrimination, and memory. Game sounds are spectrally and temporally altered to enhance cues important for speech discrimination and these enhancements are gradually reduced as a child progresses through the game. Games are completed when the child reaches an accuracy criterion (85\%), which eventually leads to the advancement from the Language to the Language to Reading program. A retrospective study of 100 children with ASD who used FFW Language along with their regular intervention program showed that almost every child who completed training showed improvements in receptive and expressive language [20].While this study suggests that FFW training can benefit children with ASD with respect to language learning, objective neural indices of auditory function were not assessed and the impact of FFW on biological functions in children with ASD were not known.

This study evaluated the effectiveness of FFW for strengthening central auditory processing of speech sounds presented in quiet and background noise conditions in high-functioning children with ASD. Given the evidence from the retrospective study of children with ASD [20], in conjunction with the reports of improvements in central auditory processing after auditory training in both the brainstem [21-24] and cortex [21,22,25-28], and considering the auditory-based training components of FFW, we hypothesized that FFW training modifies the neural processing of sound in children with ASD. We predicted that children who completed FFW exercises would show improvement in the neural encoding of speech syllables, including faster response timing, greater fidelity of the response relative to the stimulus, and more accurate pitch encoding over time. Here we present case studies of the biological impact of FFW in five children with ASD.

\section{Methods}

The Institutional Review Board of Northwestern University approved all research; informed consent by the parent or guardian and child assent were obtained. The Institutional Review Board ensures that all research is conducted in compliance with the Helsinki Declaration. Children and their families were invited to the research laboratory prior to the onset of the study to become acclimated with the testing location and equipment prior to experimental data collection. Data were compared to test-retest data from six children with ASD who did not participate in an active intervention; informed consent and assent was also obtained from these participants.

\section{Participants}

Families who participated in previous, more comprehensive research studies of neural processing of speech and prosody in children with ASD [9-11,29] were invited to participate in this study. All children were required to have (a) a formal ASD diagnosis made by a child neurologist or psychologist and to be actively monitored by their physicians and school professionals at regular intervals; (b) the absence of a confounding neurological diagnosis (e.g., active seizure disorder, cerebral palsy); (c) normal peripheral hearing as measured by air threshold pure-tone audiogram $(\leq 20 \mathrm{~dB} H \mathrm{HL}$ for octaves between 250 and $8000 \mathrm{~Hz}$ ) and normal click-evoked auditory brainstem responses (wave V latency, at 80.3 dB SPL $[16,19,20])$; (d) a full-scale mental ability score $\geq 85$ as assessed by the Wechsler Abbreviated Scale of Intelligence [30]; and (e) a Core Language score $\geq 80$ as assessed by the Clinical Evaluation of Language Fundamentals [31]. A control group of six boys with ASD (mean age $=9.00$ years, SD $=1.549$ ) who completed the entire test protocol, but who did not express interest in participating in the intensive intervention, agreed to be retested on the original protocol. The control data were used to establish test-retest reliability of the test measures. Cortical response data for control participant C3 were unavailable so the resulting mean values for cortical response measures are calculated from the remaining five subjects. See Table 1 for subject information.

Five boys (mean age $=9.40$ years, $S D=1.517$ ) underwent auditory training through FFW for a period of 5-10 weeks (mean $=7.45$ weeks). Duration was determined by each child's own progress through the Language and Language to Reading components of the program. Participants and their families each began by receiving instruction from a trained supervisor of the Scientific Learning Corporation and then transitioned to training at home once it was determined they understood the program. Training was completed when the child reached an $85 \%$ completion rate (percentage $=$ number of levels through which the child advanced) and thus duration varied across cases. Each child in the trained group began training within one year of their first session (average $=5.1$ mos, $\mathrm{SD}=4.29$ ) and were tested again approximately 1 month after having completed training (average $=34.6$ days, $\mathrm{SD}=18.11$ ). Participants were selfselected and, as a consequence, the presence or degree of deficit in auditory neurophysiological profiles before training was not controlled. See Table 1 for subject information.

The control and trained groups were not significantly different in age (Mann-Whitney $\mathrm{U}=12.5, \mathrm{p}=0.644$ ), IQ (Control mean: 104; Trained mean: 111.8; $\mathrm{U}=11$, $\mathrm{p}=0.464$ ), or language ability (Control mean: 97.33; Trained mean: 102.8; $\mathrm{U}=12.5, \mathrm{p}=0.644$ ). Further, groups did not differ significantly on test-retest duration (Control mean: 14 months; Trained mean: 9.2 months; $\mathrm{U}=5, \mathrm{p}=0.067$ ), although the trained group tended to 
Table 1 Participant characteristics

\begin{tabular}{|c|c|c|c|c|c|}
\hline \multirow[t]{2}{*}{ Subject } & \multicolumn{2}{|c|}{$\begin{array}{l}\text { FFW Training Duration } \\
\text { (days) }\end{array}$} & \multirow[t]{2}{*}{$\begin{array}{l}\text { Total Training } \\
\text { Duration }\end{array}$} & \multirow[t]{2}{*}{$\begin{array}{l}\text { Pre-post Test } \\
\text { Duration (months) }\end{array}$} & \multirow[t]{2}{*}{ Other Interventions } \\
\hline & Language & $\begin{array}{l}\text { Language to } \\
\text { Reading }\end{array}$ & & & \\
\hline S1 & 33 & 23 & 56 & 16 & Speech and dietary therapy, previously occupational therapy \\
\hline S2 & 18 & 19 & 37 & 8 & Previously occupational, speech, and music therapy \\
\hline S3 & 12 & 48 & 60 & 6 & $\begin{array}{l}\text { Social skills group, therapeutic day school, previously } \\
\text { biofeedback and occupational therapy }\end{array}$ \\
\hline S4 & 12 & 35 & 47 & 9 & $\begin{array}{l}\text { Speech, occupational, music, and dietary therapy, language } \\
\text { group and therapeutic exercise }\end{array}$ \\
\hline S5 & 25 & 36 & 61 & 7 & $\begin{array}{l}\text { Speech therapy, previously occupational therapy and social } \\
\text { skills training }\end{array}$ \\
\hline $\mathrm{C} 1$ & & & & 19 & Speech and occupational therapy \\
\hline $\mathrm{C} 2$ & & & & 15 & $\begin{array}{l}\text { Speech therapy and special education programming, formerly } \\
\text { occupational therapy }\end{array}$ \\
\hline $\mathrm{C} 3$ & & & & 14 & Speech and occupational therapy \\
\hline $\mathrm{C} 4$ & & & & 14 & Occupational therapy, social skills group \\
\hline C5 & & & & 12 & Speech and occupational therapy \\
\hline C6 & & & & 10 & Occupational and active music therapy \\
\hline
\end{tabular}

Training duration, pre-test to post-test interval, and additional interventions are listed for each participant.

have a shorter test-retest interval than the control group.

\section{Neurophysiological testing and data processing}

The auditory brainstem response was collected to both a $40 \mathrm{~ms}$ synthetic "da" stimulus which was produced in KLATT [32] and two $230 \mathrm{~ms}$ "ya" syllables with linearly ramped fundamental frequency $\left(\mathrm{F}_{0}\right)$ contours $(130-220$ $\mathrm{Hz}$ ascending; 220 - $130 \mathrm{~Hz}$ descending) that were digitally manipulated in Praat [33]. The "da" stimulus was presented in quiet ( $80 \mathrm{~dB}$ SPL) for brainstem recordings and in quiet and white background noise (+5 dB SNR) conditions for the cortical response recording. The "ya" stimuli were presented in quiet only (60 dB SPL), and were used only to collect brainstem responses. All stimuli were presented via ear inserts (brainstem "da": ER3A, Natus Medical Inc.; brainstem "ya" and cortical "da": ER-3, Etymotic Research, Elk Grove Village, IL, USA) and responses were collected with vertical electrode montages (forehead ground, active $\mathrm{Cz}$, ipsilateral earlobe reference). Brainstem responses to "da" were collected using the Bio-Logic Navigator Pro system at a $6856 \mathrm{~Hz}$ sampling rate. Responses were bandpass filtered from $100-2000 \mathrm{~Hz}$ (12 dB/octave slope), and trials with amplitude greater than $\pm 23.8 \mu \mathrm{V}$ were rejected. Three thousand accepted sweeps from each polarity were collected and averaged to form the final averaged response of 6000 sweeps. Brainstem responses to "ya" were digitized at $20,000 \mathrm{~Hz}$ by NeuroScan Acquire and bandpass filtered from $80-1000 \mathrm{~Hz}$ (12 dB/octave slope). Artifact rejection was $\pm 35 \mu \mathrm{V}$. Two replications of 2400 sweeps (1200 each polarity) were collected for each stimulus. Cortical responses to "da" were collected through
NeuroScan Acquire at a $2000 \mathrm{~Hz}$ sampling rate, bandpass filtered from $0.5-100 \mathrm{~Hz}$ (12 dB/octave slope), and artifact rejected at $\pm 65 \mu \mathrm{V}$. Approximately 1000 accepted sweeps were collected. An additional electrode on the superior canthus of the left eye was used to monitor eye blinks. Additional details regarding stimuli, brainstem and cortical response collection and analysis can be found in previous reports using identical stimulus and recording parameters [9-11,34].

The measures employed in the current paper were limited to subcortical onset response timing and cortical response timing in quiet and noise. Response timing is represented through peak latencies; for the onset response to "da" Waves $\mathrm{V}$ and $\mathrm{A}$ and for the cortical response to "da" in quiet and noise $\mathrm{P} 1$ ' and $\mathrm{N1}$ '. Additionally, subcortical pitch tracking in response to "ya" (Frequency Error for $F_{0}$ and a composite measure comprising Frequency Errors for $\mathrm{F}_{0}$ and the second harmonic $\left(\mathrm{H}_{2}\right)$ and Pitch Strength) was assessed. These measures have been shown to be significantly impaired in children with ASD relative to typically-developing children and represent the most robust differences between the groups [9-11]. All data analyses were automated using routines coded in Matlab 7.4 (The MathWorks, Inc., Natick, MA).

\section{Statistical analyses}

Responses from the trained group were judged against the amount of change expected due to chance by comparing each individual's data with the average amount of change seen in the control group. In order for a change to be deemed significant, it was required to be greater than 1 standard deviation (SD) from the mean control 
Table 2 Group data from the untrained control group.

\begin{tabular}{lccc}
\hline Measure & $\begin{array}{c}\text { Pre-test } \\
\text { Mean (SD) }\end{array}$ & Post-test & Change \\
\hline Wave V Latency (ms) & $6.59(0.24)$ & $6.67(0.21)$ & $0.07(0.08)$ \\
Wave A Latency (ms) & $7.54(0.35)$ & $7.69(0.25)$ & $0.12(0.15)$ \\
Frequency Error (Hz) & $7.69(2.31)$ & $8.51(2.54)$ & $0.65(3.35)$ \\
Pitch Tracking Composite (z score) & $-0.194(0.62)$ & $-0.291(0.95)$ & $-0.10(1.09)$ \\
P1' Latency in Quiet (ms) & $167.8(34.59)$ & $166.6(24.72)$ & $-1.20(16.48)$ \\
N1' Latency in Quiet (ms) & $255.8(43.16)$ & $258(34.24)$ & $2.20(25.82)$ \\
P1' Latency in Noise (ms) & $169.4(20.36)$ & $166.7(22.88)$ & $-2.70(13.70)$ \\
N1' Latency in Noise (ms) & $237.3(45.83)$ & $268.8(24.00)$ & $31.50(49.84)$ \\
\hline
\end{tabular}

Means and standard deviations are reported for each measure at pre-test and post-test as well as change (post-pre) for control children. Cortical response measures were available for only five of the control children.

change for that measure (see Table 2). This criterion is often employed for clinical diagnoses. The probability of showing improvement on any one measure by chance is $\sim 16 \%$; the probability of showing concurrent improvement on two measures is $\sim 2.6 \%$ and three measures is $\sim 0.4 \%$. Therefore, improvement on two or more measures would occur in less than $\sim 5 \%$ of the population simply due to chance, a standard alpha level for statistical analyses. Change was calculated as post-test value minus pre-test value and, for all variables but the composite pitch tracking measure, smaller numbers indicated more typical function (i.e., shorter latencies, less frequency error), so negative values indicated an enhancement in encoding. Because the pitch tracking composite was an average of values $\mathrm{z}$ transformed against the typically-developing (TD) mean (see [10]), enhanced encoding would be indicated by an increase in score. Additionally, subjects' responses were compared to previously-established norms in TD children to determine normalcy [9-11]. A criterion of 1.6 SD was used, which includes $\sim 95 \%$ of individuals in a population.

The FFW program does not issue skill level or percent correct scores at the onset or upon completion of the program, precluding quantitative analyses of the behavioral changes. Because the program is adaptive, success is determined by "completion" of the training exercises. Individual progress and associated changes are discussed below for each participant.

\section{Results}

\section{Subject 1}

S1 was clinically diagnosed with autism. Relative to untrained children with ASD, S1 showed improvements on subcortical and cortical response timing, but not pitch tracking. Although S1 did not demonstrate impaired brainstem processing relative to TD children at pre-training, response timing of Wave A became faster after training (improving from 1.5 SD above the TD mean to $0.25 \mathrm{SD}$ above the TD mean (Figure 1B; [9]).
Additionally, the cortical P1' response in background noise occurred earlier after training, improving from 3.9 SD to 1.6 SD (Figure 2B; [11]). On FFW Language, S1 showed consistent progress on temporal auditory processing tasks, but demonstrated persistent working memory difficulties continuing into Language to Reading.

\section{Subject 2}

S2 was clinically diagnosed with Asperger's syndrome. Like S1, S2 improved on subcortical and cortical response timing, and also approached a significant change in the pitch tracking composite relative to the control group. S2 did show marked delay in wave A timing prior to training (3.4 SD above the TD mean), but moved to within 2 SD after training (See Figure 1B). In the cortical responses, P1' and N1' latencies in quiet became earlier (improving by $1.3 \mathrm{SD}$ and $1.7 \mathrm{SD}$, respectively). He demonstrated consistent progress through the Language and Language to Reading exercises and completed training at a rapid pace (see Table 1). Behavioral speech sound discrimination and temporal processing were both noted as mild deficits at the onset of training and showed minor improvements according to the FFW report.

\section{Subject 3}

S3 was clinically diagnosed as having an ASD and, relative to the control group, improved on subcortical and cortical response timing, with no improvement in pitch tracking. Although S3 demonstrated abnormal wave A timing (4.7 SD outside the TD mean) at pre-test, his response fell within normal limits after training (0.91 SD, see Figure 1B). S3 also demonstrated poor cortical processing prior to training, with faster $\mathrm{P} 1$ ' timing in quiet and background noise after training (changes of 2.2 SD and 1.3 SD, respectively; see Figure $2 \mathrm{~B}$ ). S3 progressed rapidly through FFW Language and proceeded consistently through Language to Reading. 


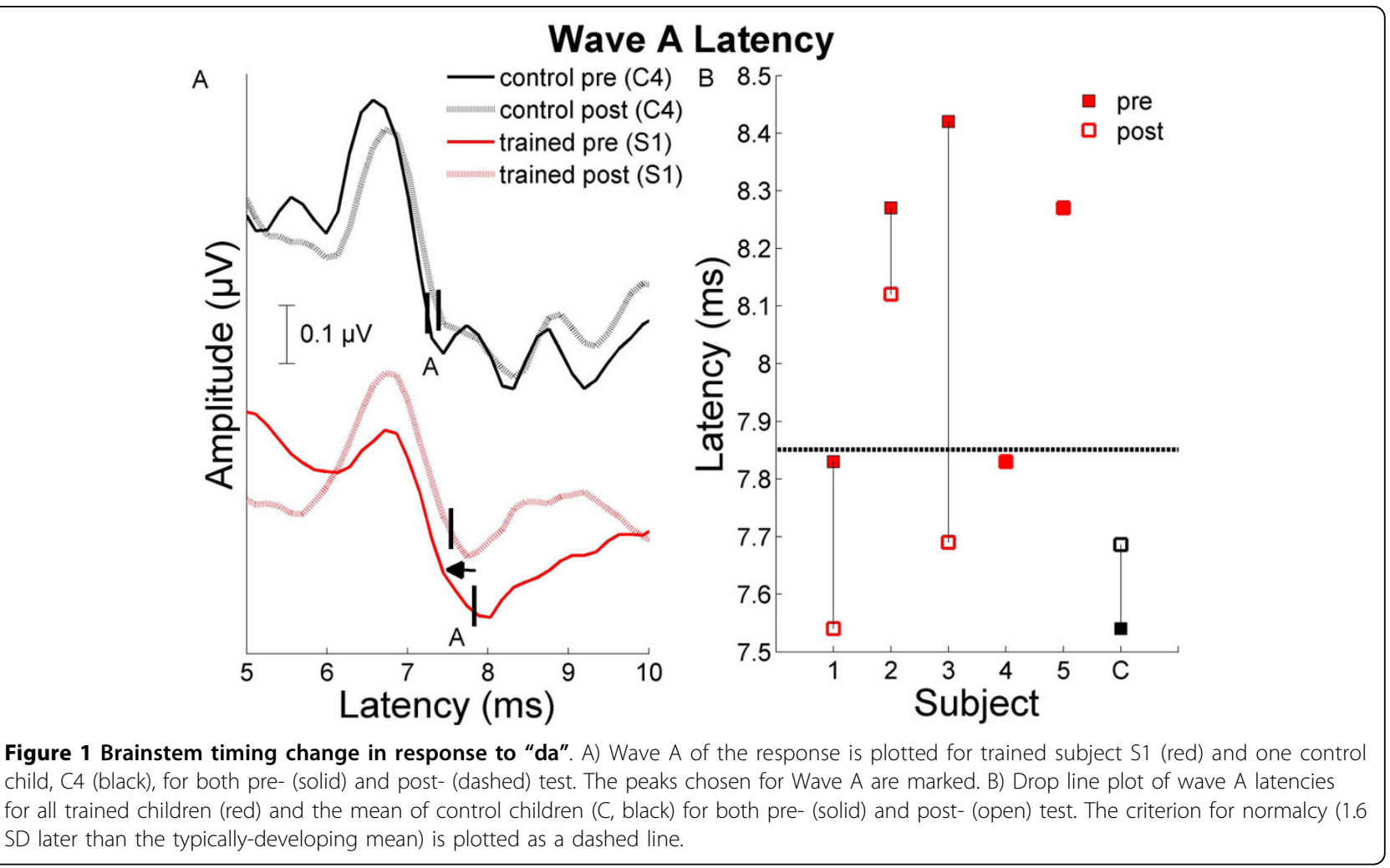

\section{Subject 4}

S4 was clinically diagnosed with Asperger's syndrome. Relative to the control group, S4 improved on cortical response timing, as well as subcortical pitch tracking accuracy. This participant showed marked impairment in both brainstem processing of "da" and pitch contour of "ya" and significant improvement in pitch processing after training relative to the control group (see Figure 3). S4 was a member of a previously reported pitchtracking 'out' group (see [10]) as calculated by a composite score of Frequency Error of the fundamental frequency, Pitch Strength, and Frequency Error of the second harmonic in response to the "ya" stimulus. After training, S4 fell within normal limits on this measure, improving from 1.9 SD to $0.95 \mathrm{SD}$ from the TD mean, although his improvement was just shy of significant relative to the control children. He did significantly improve on the Frequency Error of $\mathrm{F}_{0}$ when compared to the control group change. The improvements in pitch tracking seen in S4 are of particular interest because the majority of FFW modules do not specifically target frequency discrimination or pitch identification. While it is possible that the pitch-tracking deficits previously found in children with ASD [10] may be ameliorated or improved without specifically targeting frequency discrimination or pitch processing, according to parental report $\mathrm{S} 4$ was also participating in active music training throughout the study, which may have influenced pitch tracking improvements. Among cortical response measures, only P1' latency in background noise became earlier after training (a change of 1.5 SD; see Figure 2B). This subject progressed consistently on all FFW exercises, including Language and Language to Reading. A cautious relationship may be made between his consistent behavioral progression and neurophysiological improvements.

\section{Subject 5}

S5 was clinically diagnosed as having an ASD, without a more specific distinction. S5 showed improvements in cortical response timing relative to the control group, with no change in subcortical measures of timing or pitch tracking. He demonstrated poor transcription of "da," poor pitch tracking, and poor cortical encoding prior to training. Although brainstem measures did not change, he did show faster cortical timing after training; P1' latencies in quiet and background noise decreased significantly (changes of $1.8 \mathrm{SD}$ and $3.8 \mathrm{SD}$, respectively; see Figure 2B). Unfortunately S5 did not complete either FFW Language or Language to Reading and struggled with frustration throughout training. He was noted to have temporal auditory processing, speech sound 


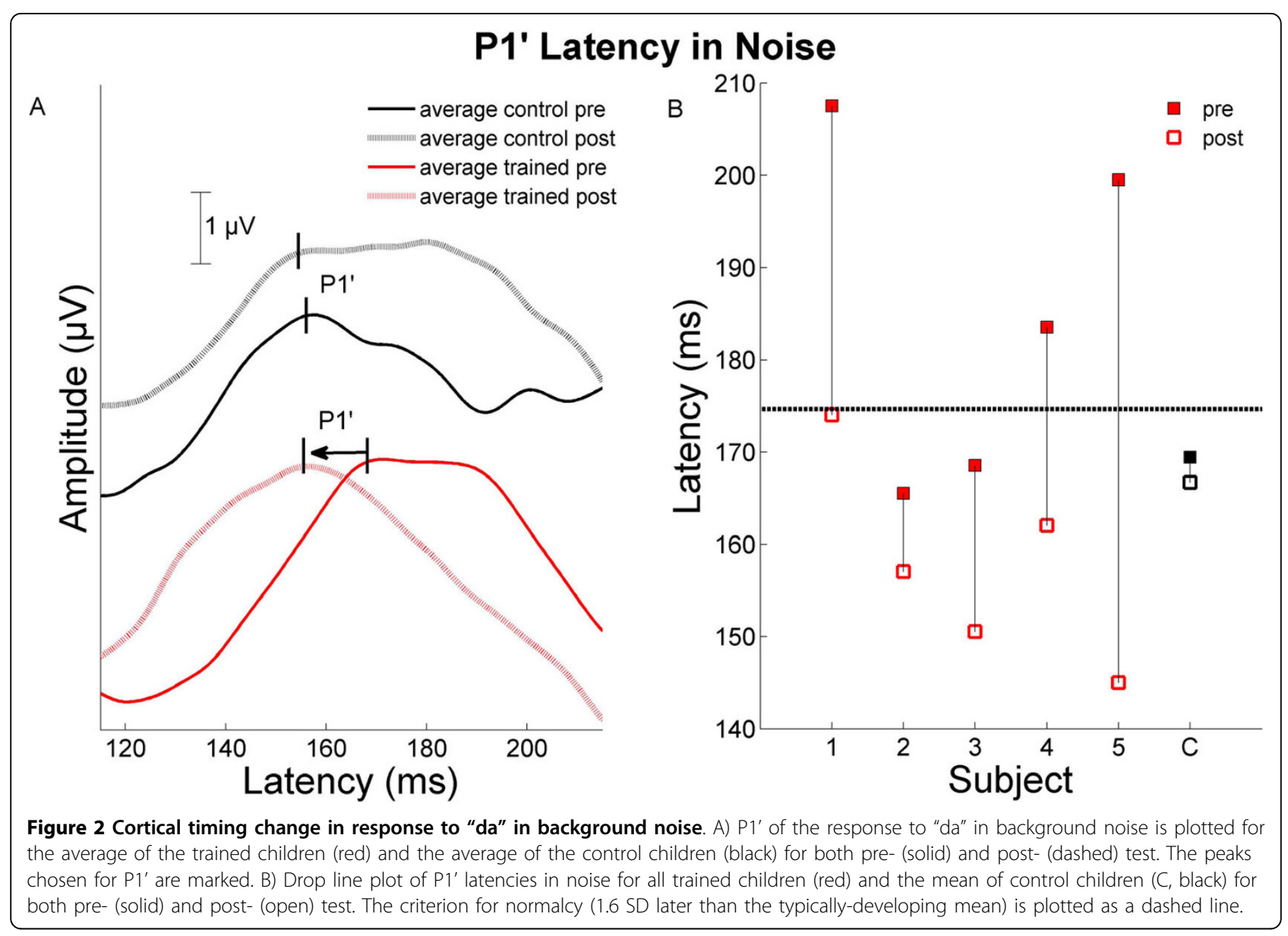

discrimination and working memory problems, consistent with his pre-training brainstem and cortical deficits. Despite his improvement on cortical response latencies, his lack of improvement on brainstem measures may have been due to his inability to complete the full training protocol.

\section{Discussion}

Although the present sample size is small, training appeared to have beneficial effects on some aspect of the neural transcription of speech in all children. Three children improved on the subcortical transcription of "da" in quiet and one child improved on pitch tracking relative to the change seen in the control children. Of the four trained children who showed brainstem improvements, two had poor transcription of "da" and/or "ya" at the pretest relative to TD children and approached or reached normal limits after training. Further, each of the five children who underwent FFW training improved on at least one measure of cortical speech processing relative to the control group, with response timing improving in both quiet and noise for some children. This study is the first to report malleability of the onset response to "da" with short-term training, plasticity of subcortical pitch tracking of the frequency contour in the "ya" stimuli, and cortical response changes in children with ASD.

Because of our limited sample size and the variability in degree of autism severity and spectrum diagnosis within our group, we are unable draw specific conclusions with respect to children with autism versus Asperger's syndrome. It is important to note that all of the children in the study were high functioning with normal intelligence and language abilities. Thus, the differentiation of diagnosis and language ability had less impact on the findings of this study, as the focus was centered on identifying neural improvements in auditory processing after training with FFW, rather than expected behavioral improvements (which were not empirically evaluated in this study). That a pattern of improvement was identified even in this heterogeneous spectrum group suggests a broader application of the training to children on the spectrum.

\section{Conclusions}

This study shows initial evidence of the efficacy of directed auditory training for improving auditory processing in a population of children with ASD. The biological 


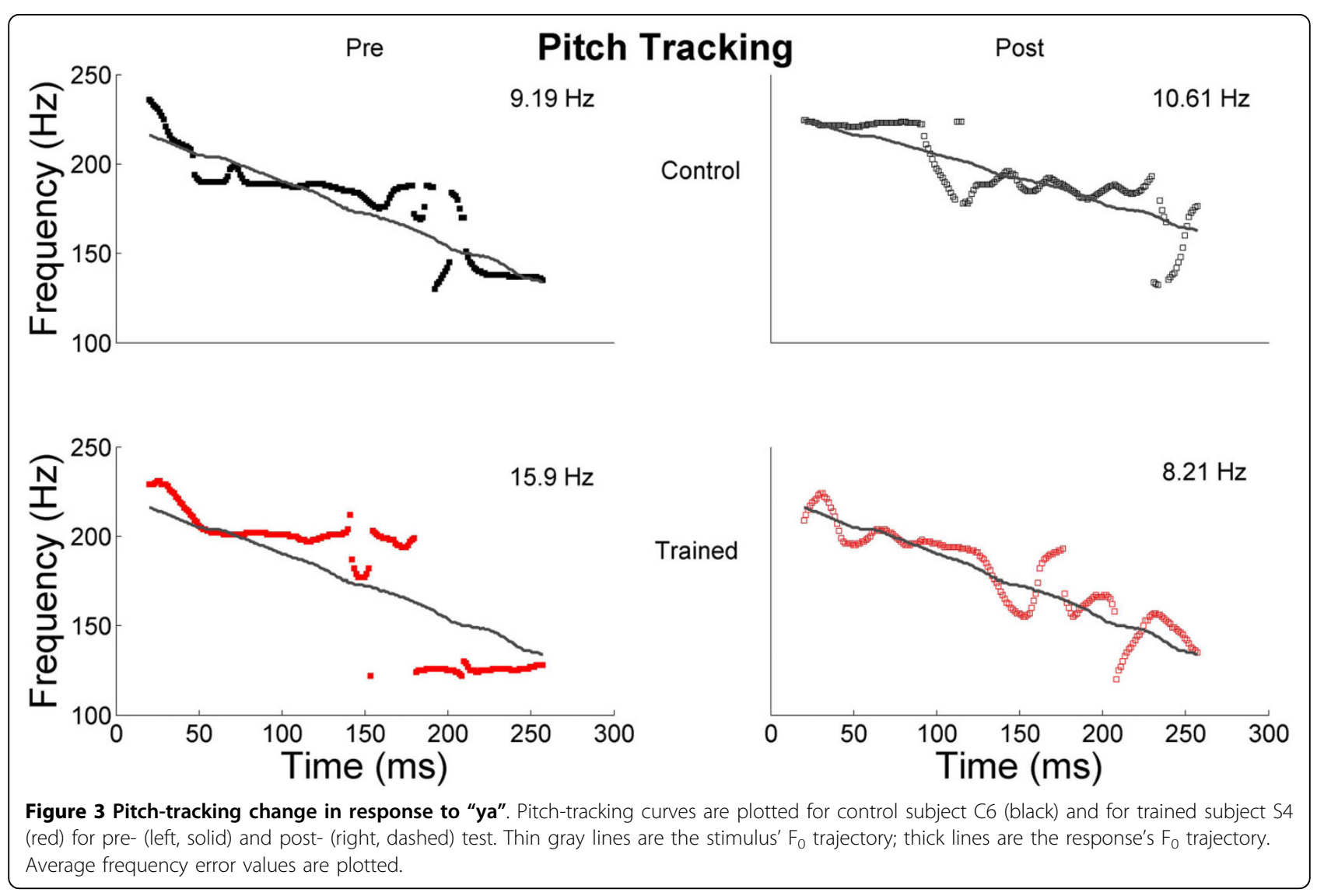

changes identified in the current study were accompanied by consistent and successful progression through FFW training. Although a correlation between days of training and neural improvements was not identified, extended use of FFW or longitudinal testing may reveal more pronounced changes in brainstem function and also behavior improvements after a delay period. This proposition is consistent with previously published reports indicating that physiological changes can precede behavioral learning [35,36]. Our findings are also consistent with previously reported auditory trainingassociated physiological changes in clinical populations $[21,23,28,37]$. These findings suggest that computerbased auditory training programs may benefit some children with ASD by impacting biological processes.

Continuation of this work with a larger cohort, more specific inclusion criteria for diagnosis, and an activecontrol group would be important to replicate and further validate these preliminary findings. Future investigations may also evaluate which brainstem deficits are predictive of gains in response to auditory training programs, and what types of behavioral improvements may be associated with training both immediately following training and after a delay period. Thus, a study that establishes the long-term maintenance of these training effects and their consequences on language function would provide valuable information for both families of children with ASD and practitioners who treat these children.

\section{Acknowledgements}

This work was supported by NIH R01 DC01510, the Roxelyn and Richard Pepper Department of Communication Sciences and Disorders, and the Hugh Knowles Center of Northwestern University. The authors would like to thank the children and their families who participated in these studies. Additionally, the authors would like to thank Barbara Trommer, M.D., for her consultation on this study and Erika Skoe for her contribution to this research, particularly in technical aspects of data processing and software development.

\section{Author details}

'Auditory Neuroscience Lab, Department of Communication Sciences,

Northwestern University, Evanston, IL, USA www.brainvolts.northwestern.edu. ${ }^{2}$ Department of Pediatrics, Rush University Medical Center, Chicago, IL, USA. ${ }^{3}$ Department of Behavioral Sciences, Rush University Medical Center, Chicago, IL, USA. ${ }^{4}$ Department of Neurobiology and Physiology, Northwestern University, Evanston, IL, USA. ${ }^{5}$ Department of Otolaryngology, Northwestern University, Evanston, IL, USA.

\section{Authors' contributions}

NR developed the study design, collected and processed the data, conducted and interpreted the statistical analyses, and prepared the manuscript. JH collected and processed the data, conducted and interpreted the statistical analyses, and prepared the manuscript. TN assisted with the data processing, statistical analyses, and interpretation and reviewed the 
drafts of the manuscript. SZ provided consultation with respect to statistical methods and interpretation and also reviewed the drafts of the manuscript. NK oversaw all aspects of the study, provided additional statistical consultation and also reviewed the drafts of the manuscript. All authors read and approved the final manuscript.

\section{Competing interests}

The authors declare that they have no competing interests.

Received: 27 May 2010 Accepted: 16 October 2010

Published: 16 October 2010

\section{References}

1. Seri S, Cerquiglini A, Pisani F, Curatolo P: Autism in tuberous sclerosis: evoked potential evidence for a deficit in auditory sensory processing. Clin Neurophysiol 1999, 110:1825-1830.

2. Tager-Flusberg H, Caronna E: Language disorders: autism and other pervasive developmental disorders. Pediatr Clin North Am 2007, 54:469-481.

3. Rapin I, Tuchman R: Autism: Definition, neurobiology, screening, diagnosis. Pediatr Clin North Am 2008, 55:1129-1146.

4. Alcantara JI, Weisblatt EJ, Moore BC, Bolton PF: Speech-in-noise perception in high-functioning individuals with autism or Asperger's syndrome. J Child Psychol Psychiatry 2004, 45:1107-1114.

5. Groen WB, van Orsouw L, Huurne N, Swinkels S, van der Gaag RJ, Buitelaar JK, Zwiers MP: Intact spectral but abnormal temporal processing of auditory stimuli in autism. J Autism Dev Disord 2009, 39:742-750.

6. Čeponienè R, Lepistö T, Shestakova A, Vanhala R, Alku P, Näätänen R, Yaguchi K: Speech-sound-selective auditory impairment in children with autism: they can perceive but do not attend. Proc Natl Acad Sci USA 2003 100:5567-5572.

7. Jansson-Verkasalo E, Čeponienè R, Kielinen M, Suominen $K$, Jäntti V, Linna S, Moilanen I, Näätänen R: Deficient auditory processing in children with Asperger Syndrome, as indexed by event-related potentials. Neurosci Lett 2003, 338:197-200

8. Lepistö T, Kujala T, Vanhala R, Alku P, Huotilainen M, Näätänen R: The discrimination of and orienting to speech and non-speech sounds in children with autism. Brain Res 2005, 1066:147-157.

9. Russo N, Nicol T, Trommer B, Zecker S, Kraus N: Brainstem transcription of speech is disrupted in children with autism spectrum disorders. Dev Sci 2009, 12:557-567.

10. Russo N, Skoe E, Trommer B, Nicol T, Zecker S, Bradlow A, Kraus N: Deficient Brainstem Encoding of Pitch in Children with Autism Spectrum Disorders. Clin Neurophysiol 2008, 119:1720-1731.

11. Russo N, Zecker S, Trommer B, Chen J, Kraus N: Effects of background noise on cortical encoding of speech in autism spectrum disorders. $J$ Autism Dev Disord 2009, 39:1185-1196.

12. Whitehouse AJ, Bishop D: Do children with autism 'switch-off' to speech sounds? An investigation using event-related potentials. Dev Sci 2008, 11:516-524.

13. Heimann M, Nelson KE, Tjus T, Gillberg C: Increasing reading and communication skills in children with autism through an interactive multimedia computer program. J Autism Dev Disord 1995, 25:459-480.

14. Sinha $Y$, Silove N, Wheeler D, Williams K: Auditory integration training and other sound therapies for autism spectrum disorders: A systematic review. Arch Dis Child 2006, 91:1018-1022.

15. Baharav E, Darling R: Case report: Using an auditory trainer with caregiver video modeling to enhance communication and socialization behaviors in autism. J Autism Dev Disord 2008, 38:771-775.

16. Williams White S, Koenig K, Scahill L: Social skills development in children with autism spectrum disorders: A review of the intervention research. J Autism Dev Disord 2007, 37:1858-1868.

17. Paul R: Interventions to improve communication in autism. Child Adolesc Psychiatr Clin N Am 2008, 17:835-856.

18. Tartaro A, Cassell J: Playing with virtual peers: Bootstrapping contingent discourse in children with autism. Proceedings of the International Conference of the Learning Science (ICLS) 2008.

19. Howard HA, Ladew P, Pollack EG, (Eds): The National Autism Center's National Standards Project "Findings and Conclusions". Randolph, MA National Autism Center 2009
20. Agocs MM, Burns MS, DeLay LE, Miller SL, Calhoun BM: Fast ForWord Language. In Treatment of language disorders in children. Edited by: McCauley RJ, Fey ME. Baltimore, MD: Brookes; 2006:471-508.

21. Hayes EA, Warrier CM, Nicol TG, Zecker SG, Kraus N: Neural plasticity following auditory training in children with learning problems. Clin Neurophysiol 2003, 114:673-684.

22. King C, Warrier CM, Hayes E, Kraus N: Deficits in auditory brainstem pathway encoding of speech sounds in children with learning problems. Neurosci Lett 2002, 319:111-115.

23. Russo N, Nicol T, Zecker S, Hayes E, Kraus N: Auditory training improves neural timing in the human brainstem. Behav Brain Res 2005, 156:95-103.

24. de Boer J, Thornton AR: Neural correlates of perceptual learning in the auditory brainstem: Efferent activity predicts and reflects improvement at a speech-in-noise discrimination task. J Neurosci 2008, 28:4929-4937.

25. Cunningham J, Nicol T, Zecker SG, Bradlow A, Kraus N: Neurobiologic responses to speech in noise in children with learning problems: deficits and strategies for improvement. Clin Neurophysiol 2001, 112:758-767.

26. Tremblay K, Kraus N, McGee T, Ponton C, Otis B: Central auditory plasticity: changes in the N1-P2 complex after speech-sound training. Ear Hear 2001, 22:79-90.

27. Tremblay $\mathrm{KL}$, Kraus $\mathrm{N}$ : Auditory training induces asymmetrical changes in cortical neural activity. J Speech Lang Hear Res 2002, 45:564-572.

28. Warrier $\mathrm{CM}$, Johnson $\mathrm{KL}$, Hayes $\mathrm{E}$, Nicol T, Kraus N: Learning impaired children exhibit timing deficits and training-related improvements in auditory cortical responses to speech in noise. Exp Brain Res 2004 157:431-441

29. Russo N, Larson CR, Kraus N: Audio-vocal system regulation in children with autism spectrum disorders. Exp Brain Res 2008, 118:111-124.

30. Woerner C, Overstreet K, (Eds): Wechsler Abbreviated Scale of Intelligence (WASI). San Antonio, TX: The Psychological Corporation 1999.

31. Semel E, Wiig EH, Secord WA: Clinical Evaluation of Language Fundamentals (4th ed.). San Antonio, TX: Harcourt Assessment, Inc 2003.

32. Klatt D: Software for cascade/parallel formant synthesizer. J Acoust SoC Am 1980, 67:971-975.

33. Boersma P: Praat, a system for doing phonetics by computer. Glot International 2002, 5:341-345.

34. Skoe $\mathrm{E}$, Kraus N: Auditory brainstem response to complex sounds: $\mathrm{A}$ tutorial. Ear Hear 2010, 31:302-324.

35. Tremblay K, Kraus N, McGee T: The time course of auditory perceptual learning: neurophysiological changes during speech-sound training. Neuroreport 1998, 9:3557-3560.

36. Penhune VB, Doyon J: Dynamic cortical and subcortical networks in learning and delayed recall of timed motor sequences. J Neurosci 2002, 22:1397-1406.

37. Stevens C, Fanning J, Coch D, Sanders L, Neville H: Neural mechanisms of selective auditory attention are enhanced by computerized training: Electrophysiological evidence from language-learning impaired and typically-developing children. Brain Res 2008, 1205:55-69.

doi:10.1186/1744-9081-6-60

Cite this article as: Russo et al:: Biological changes in auditory function following training in children with autism spectrum disorders. Behavioral and Brain Functions 2010 6:60.

\section{Submit your next manuscript to BioMed Central and take full advantage of:}

- Convenient online submission

- Thorough peer review

- No space constraints or color figure charges

- Immediate publication on acceptance

- Inclusion in PubMed, CAS, Scopus and Google Scholar

- Research which is freely available for redistribution 